\title{
Exchange New Product News
}

\section{CME and Merrill Lynch launch Rogers International Commodity Index TRAKRS}

The Chicago Mercantile Exchange (CME) announced the successful launch of the Rogers International Commodity Index Total Return Asset Contracts (TRAKRS) ${ }^{\mathrm{TM}}$ product, the eighth in a series of non-traditional futures products developed jointly with Merrill Lynch (NYSE:MER).

In a special opening procedure concluded on 2nd November, 2005, 28.7 million contracts representing more than US $\$ 716$ million in value were traded. The Rogers International Commodity Index TRAKRS started their regular trading schedule from 5th November and will trade Monday Friday from 8:30 a.m. to 3:00 p.m. Central time on the $\mathrm{CME}^{\circledR}$ Globex ${ }^{\circledR}$ electronic trading platform.

The Rogers TRAKRS is designed to provide customers with an effective way to invest in the underlying basket of commodities tracked by the Rogers International Commodity Index. This basket is broad-based and includes commodities ranging from agricultural products, such as wheat, corn and cotton, to energy products, including crude oil, petrol and natural gas, to metals and minerals, including gold, silver, aluminum and lead. The value of this basket is tracked via futures contracts on 35 different exchange-traded physical commodities listed on 10 exchanges.

TRAKRS are designed to enable investors to track an index of stocks, bonds, currencies, commodities or other financial instruments. Previous TRAKRS offerings include Long-Short Technology TRAKRS, Select 50 TRAKRS, LMC TRAKRS, Commodity TRAKRS, Euro Currency TRAKRS and Gold TRAKRS. TRAKRS are the first broad-based index products traded on a US. futures exchange that can be sold by securities brokers. Furthermore, when purchased by non-institutional investors, they are the first futures contracts that can be held in securities accounts. Each TRAKRS contract, for which CME receives significantly lower than usual clearing fees, has a notional value of approximately US $\$ 25$ at launch.

TRAKRS differ from traditional futures contracts in that they are not leveraged for most long non-institutional investors, who are required to post 100 percent of the TRAKRS market value at the time of purchase. As a result, non-institutional investors establishing long TRAKRS positions will not be subject to margin calls or any requirement to make any additional payments throughout the life of their TRAKRS positions. 
Non-institutional investors establishing short TRAKRS positions post 50 percent of the price. Short positions held by non-institutional investors are subject to certain maintenance payments if the settlement price increases substantially. Alternatively, if the settlement price decreases significantly, non-institutional investors will receive a maintenance payment. Securities brokers, subject to notice registering with the National Futures Association, are able to solicit trades in TRAKRS from non-institutional investors.

For more information on this product visit www.cme.com/trading/prd/overview _J314875.html.

\section{CME to provide first pan-Asian derivatives contract with launch of Asia 50 stock index futures}

The CME announced plans to launch a new futures contract based on the S\&P Asia 50 Index, the only Pan-Asia equity index that tracks the 50 largest stocks traded in Hong Kong, Korea, Singapore and Taiwan.

The new CME S\&P Asia 50 futures contract is expected to launch in the first quarter of 2006 exclusively on the $\mathrm{CME}^{\circledR}$ Globex $^{\circledR}$ electronic trading platform. This contract is designed specifically to help investors hedge financial risks associated with movements in the region's equity markets. It is also the first contract to be launched by CME since it agreed last month to extend and expand its existing exclusive licensing agreement with Standard \&
Poor's through 2016, with another non-exclusive year in 2017.

The S\&P Asia 50 is a large cap, free float adjusted index. Constituents are selected on the basis of size, liquidity, sector and country representation. For more information on this product, please visit www.cme.com/spasia50.

\section{CME announces five market makers for CME Eurozone HICP futures contract}

The CME announced the selection of five leading global trading firms, Barclays Capital, IXIS CIB, Lehman Brothers, Nomura International and The Royal Bank of Scotland as market makers for its new CME Eurozone HICP futures contract, which began trading on the $\mathrm{CME}^{\circledR}$ Globex ${ }^{\circledR}$ electronic trading platform on September 19, 2005.

HICP measures the level of prices for market goods and services consumed by households in Austria, Belgium, Finland, France, Germany, Greece, Ireland, Italy, Luxembourg, Netherlands, Portugal and Spain. The Eurozone HICP is an aggregate of the member states' HICPs and is targeted to cover nearly 100 per cent of all Eurozone household consumption. Harmonisation refers to the fact that the same categories and methodology are adopted for the price index in all 12 countries.

CME Eurozone HICP futures represent inflation on a notional value of $€ 1$ million for a period of 12 calendar months. Similar to the pricing of CME Eurodollar futures contracts, CME HICP futures will be quoted as 100 minus the annual inflation 
rate in the 12-month period preceding the contract month.

For more information on this product, please visit www.cme.com/hicp. Real-time price information for CME Eurozone HICP futures contracts will be available at www.cme.com/hicpprices.

\section{CBOE to launch Jumbo-DJX index options}

The CBOE announced the launch of Jumbo-DJX index options based on the Dow Jones Industrial Average (DJIA) on 11th October, 2005. The Jumbo-DJX options (ticker symbol: DXL) will be $1 / 10$ th of the value of the Dow Jones Industrial Average, but ten times larger than the DJX options contract currently traded at CBOE.

The Jumbo-DJX options will be based on $1 / 10$ th of the value of the Dow Jones Industrial Average, with a multiplier of US $\$ 100$. That is, if the DJIA is at 10,480.45, the Jumbo-DJX would have a value of 1,048.04, and notional value of DXL options would be US $\$ 104,804.50$. The currently listed DJX options are $1 / 100$ th of the value of the DJIA, and would have a value of 104.80 , and notional value of the DJX options would be about US $\$ 10,480$.

CBOE now offers a full suite of products based on the Dow Jones Industrial Average, and six other Dow Jones Indexes. In addition to DJX options, traded at CBOE since 1997, CBOE also offers options on the DIAMONDS (ticker symbol: DIA) exchange-traded fund, which is approximately $1 / 100$ th of the value of the
DJIA. All of these contracts offer investors exposure to the Dow Jones Industrial Average in one transaction, which can also offer the benefit of limited risk. Buyers of index options have pre-determined risk that is limited to the amount of premium paid.

DXL options will be cash-settled, with European-style exercise. There are no position limits, however, there are reporting requirements. The last trading day generally will be the Thursday prior to expiration. Trading hours will be 8:30 a.m. to $3: 15$ pm. Central Time. Please visit: www.cboe.com/DXL for additional contract specifications.

\section{SFE announce improvements to bond roll and half basis point pricing in three-year treasury bond futures}

Having invited market participants in April 2003 to provide written submissions to the Sydney Futures Exchange (SFE) regarding a range of potential initiatives (including a reduction in minimum price movement in the 3 Year and Bank Bill futures contracts), an extended consultation process through a representative sample of market users in the Bond Roll Focus Group was also conducted in late 2004, as well as many face to face meetings with customers.

Domestic and international customers that were consulted included fund managers, treasurers, proprietary traders, local participants, hedge funds and CTAs. In several cases written submissions were provided to SFE. Having carefully considered the diverse views of these customers on a wide range of initiatives, as well as the impact of changes on different 
customer segments, the SFE have announced the implementation of the following measures:

(1) With effect from 15th November, 2005, the opening of trading in both the morning and evening sessions for bond and interest rate futures and options contracts was 'staggered'. It is hoped this will alleviate the pressure on brokers to enter significant numbers of orders on market open. Further details regarding the timing of these changes will be issued under separate notification to the market.

(2) With effect from $5.10 \mathrm{pm}$ on 8 th March, 2006, 1/2 basis point pricing will be introduced for the period of the roll for the 3 Year Treasury Bond futures contract. 1 basis point pricing will be re-introduced from $5.10 \mathrm{pm}$ on 15th March 2006, after the expiry of the March 2006 contract. This will decrease the propensity for users to proliferate orders in an attempt to gain favourable queue position and decrease the overall costs of natural users rolling positions.

(3) With effect from $5.10 \mathrm{pm}$ on 8 th June, 2006, 1/2 basis point pricing will be re-introduced for the period of the roll for the 3 Year Treasury Bond futures contract. 1 basis point pricing will be re-introduced from $5.10 \mathrm{pm}$ on $15 \mathrm{th}$ June, 2006, after expiry of the June 2006 contract.

(4) During the 2nd half of 2006, 1/2 basis point pricing will be permanently introduced in the 3 Year Treasury Bond Futures contract. This will further decrease the overall costs of trading and provide finer pricing to create new trading opportunities for existing and new users.

(5) Timed to coincide with the permanent introduction of $1 / 2$ basis point pricing, an extension of the existing Proprietary Trading Scheme will be introduced to provide lower capitalised proprietary traders with access to lower fees at higher volumes.

The SFE also received a wide range of other suggestions from market users to also help achieve the objectives outlined above. These included removing the ability for users to view their queue position, introducing a pro-rata matching algorithm, introducing good-til-cancelled orders for the roll, de-linking the bond roll market from the outright market and introducing a pre-opening phase for the bond roll. SFE gave these suggestions thorough consideration, and while some of these solutions were deemed neither effective nor practical, SFE will continue to review further measures that may be necessary once the impact of $1 / 2$ basis point pricing has been assessed.

\section{CFE launches GAPP futures}

The CBOE Futures Exchange (CFE) launched 'Gas At The Pump' (GAPP) futures on 28th October, 2005. GAPP futures are designed to track the retail price for regular petrol paid by consumers at the pump.

The CFE launched six different GAPP contracts: one based on the average US 
price for petrol resulting from a survey of approximately 800 stations across the country, and five others based on the average price of their respective geographic regions, known as Petroleum

Administration for Defense Districts, within the United States. The contracts will be settled monthly based on the survey of retail petrol outlets conducted by the Energy Information Administration (EIA), an independent statistical and analytical agency within the US Department of Energy.

GAPP futures will be traded electronically, via CBOEdirect, and will be cleared through the triple-A rated Options Clearing Corporation (OCC). Following expiration, GAPP futures contracts will be cash-settled, meaning settlement will result in the delivery of a cash amount based on the final settlement price, determined by the surveys conducted by the EIA.

Susquehanna Investment Group has been named the Designated Primary Market Maker ('DPM') for the US, East Coast and West Coast regions GAPP contracts, and Consolidated Trading LLC has been named the Designated Primary Market Maker for the Midwest, Gulf Coast and Mountain regions GAPP contracts.

Initial contract months for GAPP futures will be December, January, March and June. In general, there will be two near-term contract months plus two additional contract months on the March quarterly cycle. Price quotations will be in cents per gallon of petrol (eg 298 cents per gallon will represent $\$ 2.98$ ). The last trading day will be the third Friday of the expiring month. Trading hours are 8:30 a.m. to 3:15 p.m., Central Time. For more details, ticker symbols and contract specifications, visit cfe.cboe.com/Gas.

\section{CBOE launch new 'weeklys' short term options based on S\&P 500 and S\&P 100 indices}

The Chicago Board Options Exchange (CBOE) launched a new type of option, 'Weeklys SM, on 28th October, 2005. There will be two initial weekly contracts - one based on the Standard \& Poor's 500 Index (SPX) and one based on the Standard \& Poor's 100 Index (OEX). Weeklys were created by $\mathrm{CBOE}$ to provide investors with an efficient means of trading options around specific time periods or certain news or events - such as economic data announcements. CBOE's one-week options will be listed on a Friday and expire the following Friday, as opposed to traditional options which have a life of months or years.

In general, Weeklys will have the same contract specifications as standard options, except for the time to expiration. The first SPX and OEX Weeklys opened on 28th October, and expired on 4th November.

Both SPX and OEX weeklys are cash-settled contracts and will offer the same continuous, two-sided quotes as standard options. SPX Weeklys will be European-style exercise with Friday AM settlement (last day of trading is Thursday), and OEX Weeklys will be American-style exercise with Friday P.M. settlement (last day of trading is Friday).

New series will be listed each Friday, expiring the following Friday, except that 
no Weeklys will be listed that would expire during the expiration week for standard options (the third Friday of each month). Ticker symbols for Weeklys will differ from the traditional options contract symbols, with letters identifying the Weekly cycle. There are no position or exercise limits; however, reporting requirements apply. Please visit www.cboe.com/Weeklys for ticker symbols and contract specifications.

\section{CBOE launch Mini-SPX index options}

The CBOE launched Mini-SPX options, based on the Standard \& Poor's 500 Stock Index, on 25th October, 2005. Mini-SPX options (ticker symbol XSP) will be 1/10th the value of the S\&P 500 Index, and will trade on CBOE's Hybrid 2.0 Trading System, which includes Remote Market Makers. Trading XSP options on CBOE's Hybrid Trading System will offer investors a smaller-sized S\&P 500 contract with the combined advantages of electronic trading and the open-outcry market on a single platform.

Mini-SPX options are a smaller sized version of SPX options that currently trade at $\mathrm{CBOE}$, and will have similar contract characteristics. The Mini-SPX options are $1 / 10$ th the value of the S\&P 500 Stock Index, and have a multiplier of US $\$ 100$ (e.g. if the S\&P 500 Index is at 1232.56, the Mini-SPX would have a value of 123.26, and notional value of the options would be US\$12,326). There are no position limits for Mini-SPX options; however, there are reporting requirements for same-side aggregate positions over
100,000 contracts. The last trading day for Mini-SPX options generally will be the Thursday prior to expiration. Trading hours will be 8:30 a.m. to 3:15 pm Central Time. Please visit www.cboe.com/miniSPX for additional contract specifications.

In addition to the new Mini-SPX options, CBOE will continue to offer full-value options on the S\&P 500 Index (SPX) and S\&P 100 Index (OEX), which have traded at CBOE since 1983, as well as options on the Standard \& Poor's

Depository Receipts (SPY), referred to as SPDRs. SPX options are full value, cash-settled, with European-style exercise. OEX options are cash-settled, with American-style exercise, and SPY options are American-style exercise, that upon exercise, settle into shares of the SPY Exchange-Traded Fund.

Index options give traders the right to buy or sell the value of an index at a predetermined price within a specific time period. Cash-settled index options result in the delivery or acceptance of a cash amount based on the settlement price of the underlying index. Options with European-style exercise generally can only be 'exercised' on the last trading day of the contract period, whereas American-style exercise allows the option holder to exercise the option on any day prior to expiration.

\section{HKEx to introduce three new stock option classes and stock futures contracts}

Hong Kong Exchanges and Clearing Limited (HKEx) announced the 
introduction of Bank of Communications Company Limited, China Netcom Corporation (Hong Kong) Limited and Ping An Insurance (Group) Company of China Limited futures and options from 7th November, 2005. Contract months of the futures and options available for trading on 7th November 2005 were November 2005, December 2005, January 2006, March 2006 and June 2006.

It was also announced that trading of China Merchants Holdings (International) Company Limited $(\mathrm{CMH})$ and Shanghai Industrial Holdings Limited (SIH) futures and options was gradually suspended from 23rd September, 2005. No new contract months and/or series on CMH and $\mathrm{SIH}$ futures and options would be introduced for trading. All existing contracts and/or series on $\mathrm{CMH}$ and $\mathrm{SIH}$ futures and options in September, October, November, December 2005 and March 2006 would be available for trading until the expiration of the respective contract months.

Investors should visit HKEx's website www.hkex.com.hk for the latest information on futures and options, including contract specifications.

\section{Deutsche Boerse announce successful launch of the Euro Buxl future}

Just over a week after the launch of the Euro-Buxl Future (FGBX) on 9th September, 2005, Eurex, the international derivatives exchange, was able to identify positive initial results. On 16th September, after only six trading days, open interest exceeded 13,000 contracts for the first time.
Open interest, or the number of open positions, is a key indicator for end customer business and for future growth of a derivatives contract. More than 50,000 contracts were traded on Eurex in just six trading days.

The contract specifications for the new Euro Buxl Futures have been set to better meet the increased hedging requirements of market participants at the very long end of the yield curve. The delivery window will be 24-35 years, previously 20-30.5 years. The notional coupon of the Euro Buxl Future is four per cent, previously six per cent. The minimum issue size for bonds included in the new Euro Buxl Future basket is 10 billion euros, previously 5 billion euros. The tick size is set at 0.02 percent (20 euros per tick).

\section{Eurex becomes first European exchange to launch volatility futures}

From 19th September, 2005, Eurex became the first exchange in Europe to offer trading in volatility futures. With these new products, Eurex will provide investors with access to volatility as an independent asset class. The volatility futures are based on the VSTOXX indices for volatility in the euro area, the VSMI index for volatility in the Swiss equity market, and the VDAX-NEW index for volatility in the German equity market. The new futures are part of a broad-based campaign by Eurex to expand its range of financial futures products and introduce new asset classes for investors around the world.

The product and innovation campaign by Eurex covers a broad range of new 
products. In addition to volatility futures, Eurex launched the 30-year BUXL future for European government bonds on 9th September, futures and options on the DJ STOXX 600 Index and DJ STOXX Mid 200 Index from 19th September, futures

on the Swiss SMIM Index and FX

Futures from 23rd September, and futures on individual equities as of 24th October.

Eurex has also extended its trading hours to $10 \mathrm{pm}$ CET, with effect from 21

November. This will enable Eurex to offer new trading opportunities to clients, to cover the trading day until the end of cash equities trading in the US, and to increase the distribution of its benchmark products in the US.

\section{Euronext.liffe launch Bclear}

Euronext.liffe, the international derivatives business of Euronext, launched Bclear, its new 'on-exchange' cleared service for the wholesale equity derivatives market, on 24 October. Bclear forms the core of three integrated services - Afirm, Bclear and Cscreen, announced in April, which will offer customers straight-through processing (STP) for wholesale equity derivatives transactions.

Bclear is the new web-based, on-exchange administration and clearing service that provides a simple way to register and process wholesale trades through Euronext.liffe to clearing at LCH.Clearnet Ltd, reducing the counter-party credit, legal and operational risks associated with off-exchange deals. Bclear will enable registration of both 'standard exchange' and 'flexible' trades in futures and options covering 12 country and pan-European indices and over 300 underlying European securities from 15 markets.

At the same time, Euronext.liffe went live with a secure, automated straight-through processing (STP) link between Cscreen, the pre-trade price discovery platform acquired by Euronext.liffe in April and Bclear, which will offer an innovative, low cost fee schedule for the booking of wholesale equity derivative transactions.

Euronext.liffe is to introduce another service, Afirm, which is geared towards providing operational efficiency for equity derivatives business conducted 'off-exchange'. Afirm will also be linked into Cscreen, providing users with a simple but efficient choice between conducting their business on- or off-exchange.

\section{New equity option class}

The Montreal Exchange announced the listing of a new equity option class, Precision Drilling Trust Units (symbol PD), at the opening of trading on 8th November, 2005.

The contract specifications for this option are available on the Exchange website at www.m-x.ca.

\section{SuperDerivatives launch interest rate option platform}

SuperDerivatives have launched SD-IR ${ }^{\mathrm{TM}}$, its new platform for pricing interest rate products, following the same blue print it 
established with the multi award-winning SD-FX system.

SuperDerivatives' products are used by numerous companies from both the buy and sell side. Almost all the banks around the world that are active in FX options use the SD-FX pricing platform, as do many corporations and hedge funds. 